\title{
Exploration of college psychological health education
}

\author{
Jiangdi \\ School of municipal and environmental engineering, \\ Jilin Jianzhu University \\ Changchun city , China \\ jiangd511@163.com
}

\author{
LinGang \\ Clothing department \\ Jilin HuaHan culture group co., LTD \\ Changchun city, China \\ Lin81@hotmail.com
}

\begin{abstract}
- college psychological health education is very important for college psychological discipline construction, lodging the important role of college psychology in the reform and the change, emphasizes two related themes of the psychological health education - the empirical application and the overall adjustment for prevention. We should cultivate talents in morality, intelligence, physique, beauty and fatigue, etc to get comprehensive development, and to have a sound personality and good social adaptation ability, therefore, the psychological health education is the foundation of training high quality talents.
\end{abstract}

Key words-college students, mental health education, countermeasures, adjust

\section{FROM THE ANGLE OF ADOLESCENT PSYCHOLOGICAL PROBLEMS TO EXPLORE THE MENTAL HEALTH EDUCATION}

American humanistic psychologist Maslow believes that mental health is the result of man's inner nature and the nature including human anatomical structure, all kinds of needs and potential of quality, or the person's psychology structure, a complete and harmonious psychological structure is the most basic guarantee of mental health. From this we can see that mental health is the rationality of the psychological structure and the normalization of psychological development in certain social environment.

Looked from the reality, students in adolescent face the pressure and challenges at least three aspects: on the one hand, the body is easy overly excited and emotional instability in development period; on the other hand, learning task is heavy and the psychological pressure is generally larger under the condition of fierce competition; at last, as the growth of the age, they are eager to have more understanding to the outside world. They need to deal with the problem more and more complex because of the gradually increase of interpersonal and the emergence of a variety of information. The three aspects of pressure are often intertwined and constant produce confliction. Although the life is rich in content, problems have also become more complex. Adolescent students are poor response to external events and poor-self-adjustment ability due to mental development, so they easily produce psychological problems in the face of various pressure and stimulation. To develop the school mental health education, therefore, has the profound significance in helping young students maintain psychological health.

First, the mental health is the basic condition of students with good psychological quality. The school mental health education can help to improve the students' psychological quality in practice. With the development of the society, people also constantly improve the understanding of their own ability. Therefore, the attention to their physiological will translate into its whole attention of the psychosomatic status. Various statistical data show that more and more students care about their mental health problems and they read books about mental health, learning the knowledge of mental health. This indicates that they are interested in mental health problems and also suggests that they are eager to promote mental health.

Second, the school mental health education can help students better adapt to society. Maintenance the students' mental health is to make them better adapt to society. Modern concept of health has regarded adapting to the society as one of the main content of health. To maintain mental health can make teenagers have a good development trend on cognition, emotion, will, and in the psychological orientation and personality traits of personality, thus to meet the social and reforming society in a objective reality, actively way, and contribute to the development of the society.

Third, carry out the school mental health education is the need of talent cultivation. Cultivating talents in the new century is the task of education in the new period and is also the task of the whole society. Competition for the future of the world, in the final analysis, is the talents competition. If young students want to foothold in the competition, they should make themselves adapt to the needs of the present new century. But the premise to become the modern talented person is to have healthy psychology. So, carry out the school mental health education, pay attention to and maintain mental health is the urgent requirement of training new century talents.

\section{THE CURRENT PROBLEMS OF COLLEGE STUDENTS MENTAL HEALTH}

According to the national professional committee of the college students' psychology for some college freshmen psychological census shows that there are serious students of psychological barriers and lead to mental disease 
accounted for $0.8 \% 2 \%, 25 \%$ to $30 \%$ of the students has certain psychological confusion or mild mental disorders; The data shows $14.6 \%$ of the students expressed that they serious thought to take the initiative to end his life within a year; $10.7 \%$ of the students had a suicide; College students' psychological obstacle survey shows it was $23.25 \%$ in the $80 \mathrm{~s}$, rose to $25 \%$ in the $90 \mathrm{~s}$ and it has been increased to $30 \%$ in recent years, teenagers has become one of the important cause of illegal and criminal due to mental disorder or mental illness. Visible, psychological health problems of college students have not be ignored and it has also become an important work in teaching management in colleges and universities. Research shows that contemporary college students have some psychological problems which were as follows.

\section{A. The deflection of social needs}

To meet the need of pleasure, they make bad behavior such as theft, robbery crime activities. For example when a city arrested two suspects who robbed a taxi driver they found both of them are the college students. The aim is to meet the high economic expenditure of the Internet and love. Some students take revenge, homicide or suicide behavior because of the failure of love and from love to hate. Some students just because of little thing, then killed or hit each other. And some students vandalized public property in order to vent dissatisfaction with school disciplinary action, etc.

\section{B. Social cognitive deviation}

Social cognitive bias refers to the individual who is selfcentered with social relations or others, without understanding or deal with the problem from the perspective of others or society. For example, college students Liu Haiyang hurt bear incident, he did things only from self desire, without considering others attitude to events, the social norms evaluation of the events.

\section{The chaos of self-consciousness}

The chaos of self-awareness refers to that students are unable to evaluate correctly themselves, appearing too high or too low self evaluation. High self-evaluation easily lead to too much ego, in the usual study and life, they show his superior behavior, leading to can't correct understanding of self. Thus they are vulnerable to inner conflict of failure and have serious emotional trauma, causing mental illness. For example, a student has been the class leader in the past, formed the self-centered, blindly optimistic psychology. After entering university his superiority gradually lose, suffering setbacks in education, love, etc. And he gradually become withdrawn, can't get along with others, and finally lead to mental illness and had to drop out of school. Low self evaluation is characterized by self exclusion, self-doubt, self-abased, no too much self-confidence, etc. when facing setbacks, they easily abandon, tired or behave aggressively.

\section{THE CAUSES OF COLLEGE STUDENTS' PSYCHOLOGICAL PROBLEMS}

\section{A. .social factor}

With the reform and opening push forward in China, the social rapid development, communication with other countries more and more closely, at the same time, various thoughts from abroad and our country's traditional ideas form sharp contrast, which impact on world outlook and outlook on life values. As the growth of the age, social experience enriching and subject consciousness enhancing, College students' competition consciousness is more and more obvious, emphasis on personal development, and collective idea gradually fade, solidarity and cooperation consciousness as well. In addition, college students thought is more radical, volatility, and is prone to mental confusion, inner conflict of values significantly because of the diversity of culture development and no definite standard.

\section{B. family factors}

Today's college students are mostly only children, grew up spoiled by their parents and elders, to enjoy a rich material life. Due to the influence of the system concept, in the process of children, most parents for their children education tend to cultural quality, and ignore the value and cultivating the psychological and personality to them. Which causes college students to be self-centered, indifferent to other people and the collective, besides, which also causes students lack of interpersonal skills, poor mental bear capacity. After entering the university, due to a series of changes of life and learning environment, they have lost their parents care, can't adapt to the collective life, and college students' psychological problems produce easily because of lack of training.

Good family education is good for students to grow, and is helpful to form good world outlook, the outlook on life and values. Practice has proved that harmonious in his home easy make children form good personality, such as positive and optimistic, cheerful and generous, humility amiable; On the other hand, disharmonious family relations easily leads a child to form cold lonely, as well as the unruly irritable personality characteristics. In addition, single parent families had a great influence on students, they are often paranoid personality, lack of confidence, psychological vulnerability, which the trauma will affect his life caused by the family.

\section{School factors}

Environment affects the person's psychology and behavior to a great extent. Good campus atmosphere can arouse the enthusiasm of students, promote students' physical and mental health, and cultivate good psychological quality. Visible, the school has vital role on individual mental health.

First, the natural environment, the school environment include building layout, landscaping and other facilities, 
such as geography, climate, environment, teaching building, library, gym, etc. The beautiful natural environment can make people feel relaxed and happy, can promote the brain active, relieve fatigue and improve mental state, promote the coordinated development of individual health of body and mind.

Second, cultural environment, school culture environment mainly includes three aspects, which are the campus culture and practice activities, teaching and scientific research activities, management and service activities. Rich campus culture can improve college students' collective sense of honor and team cooperation spirit, and cultivate student positive optimism to provide a good platform where students can fully develop themselves and exercise their own ability.

Third, interpersonal relationship, the relationship between the teachers and students, students will affect individual's mental health at campus. Practice has proved that one who has a good interpersonal relationship, get the teacher's care and trust and get the classmate's help and support can improve the self-confidence, keep good mood, and then hold a positive attitude toward life, form a optimistic, cheerful personality; Interpersonal relationship tense and lack the understanding and caring of others, which can reduce the students' adapt ability and easily make character withdrawn, inferiority, indifference, moreover ,it causes the serious psychological problems such as depression, anxiety.

\section{THE COUNTERMEASURES OF STRENGTHENING MENTAL HEALTH EDUCATION}

\section{A. To establish a whole education network among school, family and social}

We should guide family education in the case of that school education is in the priority position, thus parents can master the basic knowledge of the psychological health education to create a healthy family atmosphere and help children form the good psychological quality; Schools need to strive for the support of social forces and make full use of all kinds of social resources to carry out various forms, various channels of mental health education activities to let the students grow in the harmonious environment. School, family and social should strive to improve the teaching effect.

\section{B. Regular check and set up student psychological archives}

School mental health education workers should check students situation about student's psychological health, study, life by taking the scientific attitude, using scientific means and methods, and established psychological archives for each student. School also should improve the work of pertinence to reduce effectively the occurrence of the students' psychological obstacles.

\section{To carry out mental health education comprehensively}

First of all, establish good psychological counseling center. School also should establish a student counseling center, as well as professional teacher's guidance, to make the work to carry out well. Second, carry out mental health education courses. It can teach students mental health knowledge and psychological adjustment methods through classroom teaching and help students improve the ability to adapt to social life and form a good personality trait. Once again, carry on the propaganda, the school can popularize mental health knowledge by setting up psychological counseling hotline, mental health knowledge lectures and other activities.

\section{Carry out mental health research}

Psychology is a young discipline. The school mental health education will have new problems along with the development of The Times, such as network development, the poor students in schools, and so on. According to its own characteristics, schools can explore the new topic of psychological health education to promote the continuous development of mental health education.

\section{OVERALL ADJUSTMENT FOR PREVENTION}

In fact , many methods about mental health education in schools and other environment is difficult to achieve. Generally speaking, the training method and funds focused on adjusting of the individual internal. In recent years, the advocates of school mental health development plan calls for attention to environmental factors in students and families. Relevant research and practice, however, is lagging. In addition, the diagnosis of mental health is the first step. It also need to research some people' cycle and status who is maladjustment by emphasizing the individual spirit pathology training and state cycle, this aspect also needs to be further strengthened.

We should promote the communication between the school and the mental health organizations, emphasize the overall adjustment and treat the teenagers of severe psychological health problems. And we also should focus on the case for other countries, such as Australia, Cuba, and many western European countries which are preferred to adjust the wide range of mental health services for adolescents in school. School also should promote the international network of students' mental health and education systems, which will help the school mental health development of globalization, and help local and national change policy, increase resources, improve intelligence and school's infrastructure of adolescent mental health promotion activities.

\section{REFERENCES:}

[1] Li bin. Saving the butterfly action: college student suicide prevention [N]. China youth daily, 2004-11-24 
[2] Zhu Feng, Li Junyi. Focus on college students' mental health \# 3: mental health education approach students [EB]. Xinhuanet, 2004-07-04

[3] Wang Xinjian college students' mental health [M]. Lanzhou university press, 2000.19

[4] Liang baoyong Lv yong, li qiang, etc. The psychological health and psychological counseling encyclopedia [M]. Nankai university press, 2002.19

[5] Zheng Richang, new progress in counseling [J]. Journal of psychological science, 2000.5
[6] Strein K. Promoting mental, emotional and social health : A whole school approach .London : Routledge.2000

[7] HowardGardner.The Mind's New Sience:A History of the Cognitive Revolution. New York:

Basic Books,Ine.Prblishers.1985

[8] Cerald Corey,Theory and practice of counseling andpsychotherapy, Brooks/Cole Publishing Company, 1986

[9] Rogers, C.R.The necessary and sufficient conditions of therapeutic personality change Boston:Houghton Mifflin 1989 